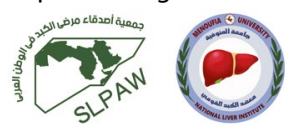

\title{
To coagulate, ligate, or both: a randomized study comparing the safety and efficacy of two endoscopic approaches for managing gastric antral vascular ectasia in cirrhotic patients
}

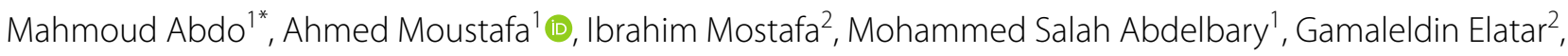
Ali Abdel Rahim², Mohamed Abdelhamid² and Hanan Abdelhalim

\begin{abstract}
Background: Gastric antral vascular ectasia (GAVE) is an uncommon but important cause of gastrointestinal bleeding in cirrhotic patients. Argon plasma coagulation (APC) is the standard therapy for GAVE. Endoscopic band ligation $(E B L)$ is an emerging, safe and effective treatment for GAVE. The best way of applying EBL in the management of GAVE is not clear yet.
\end{abstract}

Aim: We aimed to determine the safety and efficacy of APC alternating with EBL versus EBL alone for managing GAVE in cirrhotic patients.

Patients and methods: Forty cirrhotic patients with bleeding GAVE were randomized to receive either APC alternating with EBL (20 patients) or EBL alone (20 patients) until GAVE lesions are eradicated. Gastroscopy was done 6 months after eradication of GAVE lesions to document recurrence. Cessation of bleeding, rise of hemoglobin level, need for transfusion, hospitalization, complications, number of sessions, and recurrence of GAVE in both groups were statistically analyzed.

Results: Patients in both groups showed significantly high rate of bleeding cessation, improvement in hemoglobin levels, reduction in transfusions, and hospitalizations. There was no statistically significant difference regarding the recurrence of GAVE between the two groups. There were no complications seen in the combined therapy group. Twenty percent of the patients in the EBL group had complications including hypertrophied polyp formation and post-band ulcerations.

Conclusion: APC alternating with EBL and EBL alone are effective methods in the treatment of bleeding GAVE. Combined therapy has the potential to decrease the number of banding sessions and the number of rubber bands required to treat GAVE, consequently decreasing the incidence of band-related complications.

Keywords: Argon plasma coagulation, Endoscopic band ligation, Gastric antral vascular ectasia, Post-band ulcers, Hypertrophied polyp, Hemostasis

\footnotetext{
*Correspondence: Ahmedmoustafarefaat@yahoo.com

${ }^{1}$ Department of Endemic Medicine, Faculty of Medicine, Cairo University,

Cairo, Egypt

Full list of author information is available at the end of the article
}

\begin{abstract}
Introduction
Gastric antral vascular ectasia (GAVE) is an important cause of gastro-intestinal bleeding (GIB). It is an uncommon cause of overt GIB but it is frequently associated with chronic blood loss and iron deficiency anemia [1]. GAVE is typically seen in distinct patient populations.
\end{abstract}


It can occur in cirrhotic patients and cause non-variceal upper GIB.

The exact prevalence of GAVE cannot be determined due to its relatively silent presentation and association with different systemic diseases [2]. On routine upper endoscopy, GAVE is seen in 3\% of patients with advanced liver disease and $2 \%$ of those undergoing liver transplantation [3]. GAVE is considered to be responsible for $4 \%$ of non-variceal upper GIB in patients with and without portal hypertension [4].

GAVE is a vascular pathological lesion consisting of tortuous and abnormally dilated gastric mucosal capillaries (ectasia) with mural spindle cell proliferation (smooth muscle cells and myofibroblasts), focal thrombosis, and fibrohyalinosis [5]. GAVE is usually diagnosed on upper endoscopy based on the finding of reddish spots arranged either in radial stripes projecting proximally from the pylorus (watermelon stomach) or in a diffuse pattern (honeycomb stomach) or uncommonly nodular pattern (nodular antral gastropathy) [6].

For symptomatic/bleeding GAVE lesions, thermoablative endoscopic techniques (argon plasma coagulation (APC)) are considered the gold standard for control of bleeding. APC is widely available and has a relatively lower cost (compared with radiofrequency ablation and laser photocoagulation) as well as good safety profile. It achieves 80 to $100 \%$ eradication of the lesions and reduces the need for blood transfusion in 50 to $80 \%$ of the patients after 2 to 3 sessions on average [7].

Endoscopic band ligation (EBL) is an emerging therapeutic modality for GAVE with a significantly higher rate of control of bleeding with fewer treatment sessions and reduced need for blood transfusion due to greater increase in hemoglobin level post-treatment $[8,9]$. While APC effectively obliterates the superficial mucosal lesions, EBL effectively obliterates the submucosal plexus of veins. This is likely to induce a more durable response. The best way of applying EBL as compared to the gold standard APC in the management of GAVE is not clear yet.

This study was conducted to determine the safety and efficacy of APC (targeting superficial mucosal lesions) alternating with EBL (targeting submucosal angiectasis) versus EBL alone so that the best way of incorporating EBL as an emerging therapeutic modality in the management of GAVE can be elucidated.

\section{Patients and methods}

\section{Patient selection and evaluation}

This randomized prospective study was carried out on 40 cirrhotic patients after sample size calculation. These patients suffered from overt or occult bleeding from GAVE and attended or were referred to the hepatology and gastroenterology department at Theodor Bilharz Research Institute (TBRI), Giza, Egypt from the period of December 2015 till October 2017. Cirrhosis was diagnosed based on clinical, laboratory or imaging criteria. Overt upper GIB was defined as hematemesis and/or melena. Occult bleeding was defined as bleeding that is not visible to the patient or physician, resulting in either a positive fecal occult blood test, or iron deficiency anemia with or without a positive fecal occult blood test [10]. GAVE was diagnosed based on its characteristic endoscopic appearance. Red spots were almost exclusively limited to the antrum and aggregated either in linear stripes (watermelon stomach) or diffusely spread (honeycomb stomach) without a background mosaic pattern [6]. Patients were excluded if they had concomitant medical conditions commonly associated with GAVE such as: scleroderma, bone marrow transplantation or chronic renal failure. Patients were also excluded if they were on anti-platelet or anticoagulant therapy. Patients were randomized using an opaque sealed envelope method into one of two groups:

- Group I (combined therapy group): receiving alternating APC (Fig. 1a) and EBL sessions (Fig. 1b).

- Group II (EBL group): receiving EBL sessions alone.

Each group included 20 patients. TBRI's Institutional Review Board (IRB) approval was obtained (No.: 00010609 date: 16 February 2015) as well as a written informed consent from all the study participants or their proxies. The study was conforming to the ethical guidelines of the 1975 Declaration of Helsinki and its later amendments with Good Clinical Practice (GCP) guidelines.

All of the following were assessed for all patients during the initial visit:

- Full clinical assessment (history and examination).

- Laboratory investigations including complete blood count $(\mathrm{CBC})$, total bilirubin, alanine aminotransferase (ALT), aspartate aminotransferase (AST), albumin, and international normalized ratio (INR)

- Abdominal ultrasonography

- Child-Turcotte-Pugh (CTP) score

- Upper gastro-intestinal endoscopy

- Treatment strategy (based on randomization after adequate stabilization)

\section{Endoscopic procedures}

Standard APC equipment was used, consisting of a highfrequency electrosurgical generator (ICC 200; ERBE, Tübingen, Germany), an automatically regulated argon 

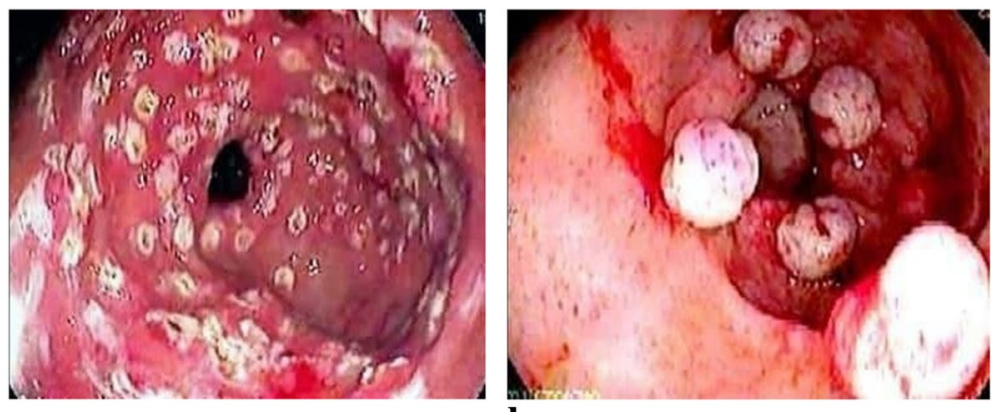

a

b

Fig. 1 a The appearance of gastric antral mucosa after performing APC. $\mathbf{b}$ The appearance of gastric antral mucosa after performing EBL

source (APC 300) and a flexible APC probe. The APC probe was a $2.3 \mathrm{~mm}$ Teflon-coated catheter with a heatresistant ceramic tip, which could be passed through the working channel of the endoscope. Electrical power was 40 to $60 \mathrm{~W}$ and argon gas flow was $2 \mathrm{~L} / \mathrm{min}$. APC was applied to the lesions beginning at the pylorus and proceeding proximally (Fig. 1a).

EBL was carried out using a pneumoactivate device (Sumitomo Bakelite, Tokyo, Japan) applying ligation bands on the GAVE lesions. Rubber bands were applied to the abnormal distal antral mucosa in circular manner around pylorus. Distance between bands was about 2-3 $\mathrm{cm}$ and extending proximally until as much as possible of the abnormal-appearing mucosa is ligated (Fig. 1b). Endoscopic procedures were performed by a single operator.

Sessions were performed every 3 weeks until eradication of GAVE lesions is achieved. Patients in the two groups were re-evaluated in case of recurrence of overt or occult bleeding in between sessions.

\section{Follow-up}

Hemoglobin level was evaluated on a monthly basis. Packed red cell transfusion was done when indicated. Upper GI endoscopy was performed in case of overt or occult bleeding and recorded if the source was from GAVE lesions. Follow-up endoscopy was scheduled 6 months after eradication of GAVE lesions to document recurrence. Recurrence of GAVE was defined as endoscopically proven recurrence of GAVE lesions.

\section{Statistical analysis}

Post-treatment outcome data were statistically analyzed to compare both treatment approaches as regards the occurrence of bleeding, hemoglobin level, packed red cell transfusion, need for hospitalization, complications, number of treatment sessions, and recurrence of GAVE and subsequently determining the safety and efficacy of both approaches. Results were expressed as means \pm standard deviation or in percentage (\%) in categorical values. Comparison between the two groups was performed using ANOVA with post hoc least significance difference test. Comparison between categorical data was performed using chi-square test. Spearman rank correlation coefficient was used to determine significant correlations among different parameters. The data were considered significant if $P$ values were $<0.05$ and highly significant if $<0.01$. Statistical analysis was performed with the aid of the SPSS computer program (version 20 windows, Armonk, NY: IBM Corp.).

\section{Results}

\section{Patients' characteristics and demographics}

A total of 40 cirrhotic patients suffering from GAVE who met the inclusion criteria were enrolled in this study. Twenty patients were randomized to group I who received APC alternating with EBL sessions (combined therapy group), and the other twenty patients were randomized to group II who received EBL sessions (EBL group).

There were no significant differences between the two groups regarding the clinical features of the disease, mean age, gender, and patients' residence area. The most common clinical features of the disease in the two groups were: pallor (100\% in combined group versus $90 \%$ in EBL group), previous treatment for esophageal varices $(45 \%$ in combined group versus $40 \%$ in EBL group), and bleeding tendency (45\% in combined group versus $40 \%$ in EBL group) (Table 1). The mean age of the patients was 57.75 \pm 7.51 in the combined therapy group, and $57.35 \pm 8.28$ in the EBL group. The female to male ratio was 9:11 in the combined therapy group, and 7: 13 in the EBL group.

All recruited patients were cirrhotic. It was hepatitis $C$ virus (HCV)-related in $90 \%$ of patients in combined therapy group and $100 \%$ in EBL group (Table 1). Forty \% of patients in combined group and $40 \%$ in EBL group were 
Table 1 Patients' characteristics at baseline $(n=40,100 \%)$

\begin{tabular}{|c|c|c|c|c|c|}
\hline \multirow[t]{2}{*}{ Comparative factors } & \multicolumn{2}{|c|}{ Group I: combined therapy group } & \multicolumn{2}{|c|}{ Group II: EBL group } & \multirow[t]{2}{*}{$P$ value } \\
\hline & Mean/Count & $\% / \pm S D$ & Mean/count & $\% / \pm S D$ & \\
\hline \multicolumn{6}{|l|}{ History and clinical finding } \\
\hline History of hepatic encephalopathy & 4 & $20 \%$ & 5 & $25 \%$ & 0.705 \\
\hline History of bilharziasis & 5 & $25 \%$ & 4 & $20 \%$ & 0.705 \\
\hline Previous treatment of oesophageal varices & 9 & $45 \%$ & 8 & $40 \%$ & 0.749 \\
\hline $\begin{array}{l}\text { Bleeding tendency (epistaxis, bleeding gums, } \\
\text { ecchymotic patches at venipuncture sites) }\end{array}$ & 9 & $45 \%$ & 8 & $40 \%$ & 0.749 \\
\hline Pallor & 20 & $100 \%$ & 18 & $90 \%$ & 0.136 \\
\hline Palmar erythema & 7 & $35 \%$ & 8 & 405 & 0.744 \\
\hline Lower limb edema & 5 & $25 \%$ & 8 & $40 \%$ & 0.311 \\
\hline Jaundice & 7 & $35 \%$ & 5 & $25 \%$ & 0.490 \\
\hline Spider nevi & 5 & $25 \%$ & 11 & $55 \%$ & 0.053 \\
\hline Dilated abdominal veins & 3 & $15 \%$ & 3 & $15 \%$ & 1 \\
\hline Fever & 2 & $10 \%$ & 3 & $15 \%$ & 0.633 \\
\hline \multicolumn{6}{|l|}{ Demographic features } \\
\hline Age (years) & 57.75 & \pm 7.51 & 57.35 & \pm 8.28 & 0.874 \\
\hline Sex (female/male) & $9 / 11$ & $45 \% / 55 \%$ & $7 / 13$ & $35 \% / 65 \%$ & 0.519 \\
\hline Residence (urban/rural) & $7 / 13$ & $35 \% / 65 \%$ & $5 / 15$ & $25 \% / 75 \%$ & 0.490 \\
\hline \multicolumn{6}{|l|}{ Etiology of liver cirrhosis } \\
\hline $\mathrm{HCV}$ & 18 & 90 & 20 & $100 \%$ & 0.349 \\
\hline HBV & 1 & $5 \%$ & 0 & $0 \%$ & \\
\hline Non-viral & 1 & $5 \%$ & 0 & $0 \%$ & \\
\hline \multicolumn{6}{|l|}{ Child-Turcotte-Pugh classification } \\
\hline Class A & 8 & $40 \%$ & 8 & $40 \%$ & 0.920 \\
\hline Class B & 6 & $30 \%$ & 5 & $25 \%$ & \\
\hline Class C & 6 & $30 \%$ & 7 & $35 \%$ & \\
\hline \multicolumn{6}{|l|}{ Laboratory findings } \\
\hline $\operatorname{ALT}(U / L)$ & 45.60 & \pm 16.46 & 48.10 & \pm 21.72 & 0.978 \\
\hline AST (U/L) & 56.65 & \pm 22.80 & 50.85 & \pm 20.22 & 0.464 \\
\hline Albumin $(\mathrm{g} / \mathrm{dL})$ & 2.68 & \pm 0.59 & 2.73 & \pm 0.63 & 0.587 \\
\hline Total bilirubin (mg/dl) & 2.28 & \pm 1.24 & 2.47 & \pm 1.69 & 0.924 \\
\hline Prothrombin concentration & 58.80 & \pm 12.79 & 60.80 & \pm 17.36 & 0.498 \\
\hline White blood cell $\left(\times 10^{3} / \mathrm{mm}^{3}\right)$ & 5.46 & \pm 2.6 & 5.48 & \pm 2.6 & 0.968 \\
\hline Platelet count $\left(10^{3} / \mathrm{mm}^{3}\right)$ & 84.80 & \pm 29.844 & 91.80 & \pm 61.10 & 0.756 \\
\hline Hemoglobin (g/dL) & 6.86 & \pm 1.25 & 7.71 & \pm 1.66 & 0.074 \\
\hline
\end{tabular}

Unless otherwise stated numerical data are expressed as mean (SD)

Abbreviations: $A L T$ alanine aminotransferase, $A S T$ aspartate aminotransferase, $E B L$ endoscopic band ligation, $H B V$ hepatitis $B$ virus; $H C V$ hepatitis $C$ virus

$P>0.05=$ not significant

CTP score class A, 30\% of patients in combined group and $20 \%$ in EBL group were class B, and 30\% of combined group and $35 \%$ of the EBL group were class $C$ (Table 1).

\section{Pretreatment endoscopy}

Endoscopic picture of GAVE revealed that 17 patients (85\%) in the combined therapy group, and 15 patients (75\%) in the EBL group had punctate diffuse type of GAVE. On the other hand, classic type of GAVE resembling watermelon appearance was detected in three patients (15\%) in combined therapy group, and in five patients (25\%) in the EBL group. Varices were detected in a total of nine patients (45\%) in the combined therapy group, and in eight patients (40\%) in EBL group, with no significant difference between the two groups (Table 2).

\section{Treatment sessions}

Number of treatment sessions was significantly lower in the EBL group than in the combined therapy group (a mean of $3.25 \pm 1.07$ sessions in combined therapy group, 
Table 2 Ultrasound and endoscopic findings in the two studied groups ( $n=40,100 \%)$

\begin{tabular}{|c|c|c|c|c|c|}
\hline \multirow[t]{2}{*}{ Comparative factors } & \multicolumn{2}{|c|}{ Group I: combined therapy group } & \multicolumn{2}{|c|}{ Group II: EBL group } & \multirow[t]{2}{*}{$P$ value } \\
\hline & Mean/count & $\% / \pm S D$ & Mean/count & $\% / \pm S D$ & \\
\hline \multicolumn{6}{|l|}{ Liver size } \\
\hline Normal & 15 & $75 \%$ & 11 & $55 \%$ & 0.403 \\
\hline Shrunken & 3 & $15 \%$ & 6 & $30 \%$ & \\
\hline Enlarged & 2 & $10 \%$ & 3 & $15 \%$ & \\
\hline Cirrhosis & 20 & $100 \%$ & 20 & $100 \%$ & 1 \\
\hline Focal lesions & 1 & $5 \%$ & 0 & $0 \%$ & 0.311 \\
\hline Portal fibrosis & 3 & $15 \%$ & 6 & $30 \%$ & 0.256 \\
\hline Splenomegaly & 18 & $90 \%$ & 13 & $65 \%$ & 0.490 \\
\hline Collaterals & 6 & $30 \%$ & 6 & $30 \%$ & 1 \\
\hline Ascites & 11 & $55 \%$ & 11 & $55 \%$ & 0.861 \\
\hline Portal vein dilatation & 17 & $85 \%$ & 12 & $60 \%$ & 0.077 \\
\hline \multicolumn{6}{|l|}{ Type of bleeding from GAVE } \\
\hline Hematemesis \pm melena & 5 & $25 \%$ & 4 & $20 \%$ & 0.927 \\
\hline Melena alone & 12 & $60 \%$ & 13 & $65 \%$ & \\
\hline Occult bleeding & 3 & $15 \%$ & 3 & $15 \%$ & \\
\hline \multicolumn{6}{|l|}{ Endoscopic picture of GAVE } \\
\hline Punctuate type & 17 & $85 \%$ & 15 & $75 \%$ & 0.429 \\
\hline Classic type & 3 & $15 \%$ & 5 & $25 \%$ & \\
\hline
\end{tabular}

Data are expressed as $n$ (\%)

$P>0.05=$ not significant

and $1.95 \pm 0.76$ sessions in EBL group) $(P=0.001)$. Endoscopic sessions were carried out every 3 weeks until endoscopic evidence of eradication of GAVE lesions was obtained (Table 3).

The mean number of banding sessions was $1.5 \pm 1.50$ and $1.95 \pm 0.76$ in combined therapy group and EBL group, respectively. The mean number of banding sessions and of the number of rubber bands used was significantly lower in the combined therapy group than in the EBL group ( $P$ values $=0.034$ and 0.042 , respectively). The mean number of rubber bands was $8.30 \pm 3.53$ (range $5-12)$ in the combined therapy group, and was $11.35 \pm$ 5.44 (range 5-18) in EBL group.

Bleeding cessation rate was similar in both groups with $85 \%$ and $90 \%$ in combined therapy and EBL groups, respectively $(P=0.676)$. Recurrence rate was similar in both groups with $15 \%$ in combined therapy group and $10 \%$ in EBL group $(P=0.676)$. Hemoglobin levels significantly increased in both groups post-treatment $(P=$ 0.001), with higher hemoglobin values seen in the EBL group. Number of hospitalizations and blood transfusions significantly decreased in both groups $(P$ value $=$ 0.003 and 0.001 , respectively) (Table 4 ). No complications were experienced in the combined therapy group, whereas four patients (20\%) in EBL group experienced post treatment complications (hypertrophied polyp formation (Fig. 2a) and post-band ulcerations (Fig. 2b)).

\section{Discussion}

APC is the standard treatment for GAVE. EBL is an emerging, effective and safe therapeutic modality for GAVE. The rationale for use of EBL is linked to its effect on the submucosal vascular plexus while treatment with APC is mainly directed to lesions in the mucosal layer and this may explain why EBL may theoretically be more effective at obliterating GAVE compared to APC with a more durable response [11].

This study was conducted to compare the safety and efficacy of combining both APC and EBL in alternating sessions with EBL alone. The idea of combining APC and EBL in alternating sessions is to treat lesions in the mucosal layer with APC then to treat the deeper submucosal resistant lesions using EBL. This may help to gain the benefits of both techniques and reduce the side effects associated with the use of EBL by reducing the number of rubber bands used.

In this prospective randomized study, we compared the efficacy and safety of combination therapy of APC and EBL to EBL alone in 40 cirrhotic patients who suffered from GAVE.

Most of the patients in the two groups showed punctuate (diffuse) type of GAVE which was detected in 17 patients (85\%) in the combined therapy group and in 15 patients $(75 \%)$ in the EBL group. This could be explained by the fact that our patients were cirrhotic and the 
Table 3 Treatment outcome $(n=40,100 \%)$

\begin{tabular}{|c|c|c|c|c|c|}
\hline \multirow[t]{2}{*}{ Comparative factors } & \multicolumn{2}{|c|}{$\begin{array}{l}\text { Group I: combined therapy } \\
\text { group }\end{array}$} & \multicolumn{2}{|c|}{ Group II: EBL group } & \multirow[t]{2}{*}{$P$ value } \\
\hline & Mean/count & $\% / \pm \mathrm{SD}$ & Mean/count & $\% / \pm S D$ & \\
\hline \multicolumn{6}{|l|}{ Treatment sessions } \\
\hline Mean number of treatment sessions & 3.25 & \pm 1.07 & 1.95 & \pm 0.76 & $0.001 *$ \\
\hline Mean number of banding sessions & 1.5 & \pm 1.5 & 1.95 & \pm 0.76 & $0.034^{*}$ \\
\hline Mean bands number used & 8.3 & \pm 3.53 & 11.35 & \pm 5.44 & $0.042^{*}$ \\
\hline Recurrence of bleeding from GAVE (after 6 months of follow-up) & 3 & $15 \%$ & 2 & $10 \%$ & 0.676 \\
\hline Cessation of bleeding (after 6 months of follow-up) & 17 & $85 \%$ & 18 & $90 \%$ & \\
\hline \multicolumn{6}{|l|}{ Treatment outcomes } \\
\hline Hemoglobin $(\mathrm{g} / \mathrm{dl})$ at baseline & 6.86 & \pm 1.25 & 7.71 & \pm 1.66 & 0.074 \\
\hline Hospitalization at baseline & 1.60 & \pm 1.00 & 1.50 & \pm 1.05 & 0.641 \\
\hline Blood transfusion at baseline & 3.90 & \pm 2.55 & 3.20 & \pm 2.24 & 0.360 \\
\hline Hemoglobin (g/dl)(6 months follow-up) & 9.78 & \pm 1.68 & 10.04 & \pm 1.93 & 0.646 \\
\hline Hospitalization (6 months follow-up) & 0.40 & \pm 0.88 & 0.40 & \pm 0.82 & 0.794 \\
\hline Bood transfusion (6 months follow-up) & 0.70 & \pm 1.98 & 0.95 & \pm 1.88 & 0.462 \\
\hline The mean changes in hemoglobin ( $\mathrm{g} / \mathrm{dl})$ & 2.92 & \pm 1.50 & 2.33 & \pm 1.74 & 0.258 \\
\hline The mean changes in hospitalization & -1.2 & \pm 1.24 & -1.10 & \pm 0.91 & 0.773 \\
\hline The mean changes in transfusion & -3.20 & \pm 2.28 & -2.25 & \pm 1.52 & 0.130 \\
\hline
\end{tabular}

Unless otherwise stated numerical data are expressed as mean (SD). Statistically significant values are in bold

$P>0.05=$ not significant, ${ }^{*} P<0.05=$ significant, ${ }^{*} P<0.01=$ highly significant. Baseline transfusion and hospitalization applies to the last 6 months preceding recruitment

Table 4 Comparison between pre- and post-treatment data in the two groups

\begin{tabular}{|c|c|c|c|c|c|c|}
\hline \multirow[t]{2}{*}{ Comparative factors } & \multicolumn{3}{|c|}{ Group I: combined therapy group } & \multicolumn{2}{|c|}{ Group II: EBL group } & \multirow[t]{2}{*}{$P$ Value } \\
\hline & Pre-treatment & $\begin{array}{l}\text { Post treatment (after } 6 \\
\text { months follow-up) }\end{array}$ & $P$ value & Pre-treatment & $\begin{array}{l}\text { Post treatment (after } 6 \\
\text { months follow-up) }\end{array}$ & \\
\hline Hemoglobin (g/dl) & $6.86 \pm 1.25$ & $9.78 \pm 1.68$ & $0.001^{* *}$ & $7.71 \pm 1.66$ & $10.04 \pm 1.93$ & $0.001^{* *}$ \\
\hline Hospitalization & $1.60 \pm 1.00$ & $0.40 \pm 0.88$ & $0.003^{* *}$ & $1.50 \pm 1.05$ & $0.40 \pm 0.82$ & $0.003^{* *}$ \\
\hline Transfusion & $3.90 \pm 2.55$ & $0.70 \pm 1.98$ & $0.001 * *$ & $3.20 \pm 2.24$ & $0.95 \pm 1.88$ & $0.001^{* *}$ \\
\hline
\end{tabular}

Data are expressed as mean (SD). Statistically significant values are in bold

$P>0.05=$ not significant, ${ }^{*} P<0.05=$ significant, ${ }^{* *} P<0.01=$ highly significant

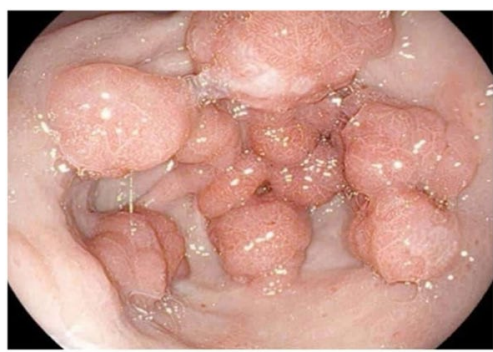

a

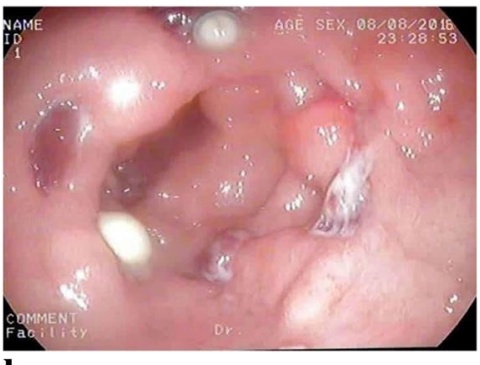

b

Fig. 2 a Post-banding hypertrophied polyp formation seen in the antral mucosa complicating EBL. b Post-banding ulceration seen in the antral mucosa complicating EBL 
punctate type is the predominant type of GAVE in cirrhotic patients. This is consistent with previous studies that reported that the punctate type of GAVE is more common in cirrhotics. Punctate type of GAVE was noted in $75 \%$ of the patients in the study by Abdelhalim et al., and in $76.5 \%$ of the patients in the study by Lecleire et al. $[9,12]$.

The mean age of cirrhotic patients who presented with GAVE was $57.75 \pm 7.51$ and $57.35 \pm 8.28$ in the combined therapy group and EBL group, respectively. This is in agreement with two other similar studies performed on cirrhotic Egyptian patients with a mean age of 54 and 55 years $[9,13]$. Other studies reported older age for patients with GAVE [14].

The younger age of GAVE patients may be related to the higher prevalence of liver cirrhosis in this age group secondary to the high prevalence of HCV in Egypt. All recruited patients were cirrhotic. It was $\mathrm{HCV}$-related in $90 \%$ of patients in combined therapy group and $100 \%$ in EBL group.

Severe anemia was observed in patients of both groups and this was due to either acute or chronic blood loss from GAVE. This is in agreement with Naga et al. and Zulli et al. who stated that cirrhotic patients with GAVE frequently had significant blood loss and anemia often resulting in repeated transfusion $[13,15]$.

In our study, the mean value of blood transfusion prior to enrollment in the study was $3.90 \pm 2.55$ and $3.20 \pm$ 2.24 in the combined therapy group and EBL group, respectively. This value was significantly decreased to a mean value of $0.70 \pm 1.98$ in the combined therapy group and to $0.95 \pm 1.88$ in the EBL group with $P$ value $=0.001$ after six months of follow up denoting that both approaches are highly effective in controlling bleeding from GAVE.

In our study, treatment of GAVE with EBL had required statistically significant fewer treatment sessions as compared to the combined therapy. This may be explained by the fact that EBL is more effective than APC in obliterating the sub-mucosal plexus of veins and this is reflected on the overall efficacy of the procedure and hence the fewer number of treatment sessions. In a meta-analysis by Chalhoub et al., EBL appears to be both safe and effective in the management of GAVE-related blood loss. The limited literature suggests that compared to endoscopic thermal techniques, the use of EBL is associated with significantly lower transfusion requirements and shows a trend towards more encouraging post-procedural hemoglobin changes and lower number of procedures required to obliterate GAVE. Using EBL in the treatment of GAVE has the potential to reduce the healthcare burdens and costs [16].
Furthermore, in our study, the use of APC significantly decreased the number of required banding sessions in the combined therapy group as compared to the EBL group (the mean number of banding sessions was $1.5 \pm$ 1.5 in combined therapy group as compared to $1.9 \pm 0.76$ in EBL group).

The mean number of rubber bands was significantly lower in the combined therapy group than in the EBL group. This may be explained by the fact that APC successfully treats the superficial mucosal lesions and the application of EBL is limited to residual areas which were deeper and refractory to APC.

Patients in both groups showed significantly high rate of bleeding cessation, significant improvement in hemoglobin levels at the end of the follow-up period, and significant reduction in the number of packed red cell transfusions and number of hospitalizations. There was no statistically significant difference regarding the recurrence of GAVE between the two study groups.

Complications of thermal therapies, including APC, in the treatment of GAVE have been reported such as bleeding, perforation, and even death [17]. However, in our study there were no complications seen in the combined therapy group. On the other hand, $20 \%$ of the patients in the EBL group had complications including hypertrophied polyp formation and prolonged post-band ulcerations. This was in concordance with previously reported data [18].

Our results showed that the incidence of complications correlated with the number of applied rubber bands which was significantly lower in the combined therapy group than in the EBL group.

Our study has limitations. Small number of recruited patients makes interpretation of results difficult. All the recruited patients were cirrhotic. Whether our results can be extrapolated to GAVE associated with other medical conditions is not clear and needs validation. Larger head-to-head studies comparing APC, EBL, and combined approaches are needed to confirm our results.

\section{Conclusion}

Combined therapy (APC alternating with EBL) and EBL alone are effective methods in the treatment of bleeding GAVE in Egyptian cirrhotic patients. Combined therapy has the potential to decrease the number of banding sessions and decrease the number of rubber bands required to treat GAVE, consequently decreasing the incidence of band-related complications. This was at the expense of overall more number of treatment sessions. So, in mild cases when a small number of rubber bands seems to be required, it may be advisable to start with EBL alone, while in severe cases where a large number of rubber 
bands seems to be required, it may be advisable to use combination therapy of APC alternating with EBL.

\begin{abstract}
Authors' contributions
All authors have substantially contributed to the conception and design, acquisition of data, data analysis and interpretation. All authors have agreed on the content of the manuscript. Mahmoud Abdo, MD: interpretation of data and manuscript writing. Ahmed Moustafa, MD: interpretation of data, manuscript revision and submission Ibrahim Mostafa, MD: Conception and study design, data analysis and interpretation Mohammed Salah Abdelbary, MD: Conception and study design, data analysis and interpretation Gmaleldin Elatar, MD: interpretation of statistical analysis. Ali Abdel Rahim: Data collection and acquisition. Mohamed Abdelhamid, MD: Performed the endoscopic techniques Hanan Abdelhalim, MD: Study design, conception and manuscript revision. The author(s) read and approved the final manuscript.
\end{abstract}

\section{Funding}

None declared

\section{Declarations}

\section{Competing interests}

All authors declare that they have no competing interests.

\section{Author details}

${ }^{1}$ Department of Endemic Medicine, Faculty of Medicine, Cairo University, Cairo, Egypt. ${ }^{2}$ Theodor Bilharz Research Institute (TBRI), Giza, Egypt.

Received: 30 September 2021 Accepted: 13 January 2022

Published online: 20 January 2022

\section{References}

1. Mathurin SA, Agüero AP, Dascani NA, Prestera JA, Gianserra C, Londero E, Chiorra C (2009) Anemia en pacientes internados con cirrosis: prevalencia, significación clínica y factores predictivos [Anemia in hospitalized patients with cirrhosis: prevalence, clinical relevance and predictive factors]. Acta Gastroenterol Latinoam 39(2):103-111

2. Gostout CJ, Viggiano TR, Ahlquist DA, Wang KK, Larson MV, Balm R (1992 Oct) The clinical and endoscopic spectrum of the watermelon stomach. J Clin Gastroenterol 15(3):256-263. https://doi.org/10.1097/00004836199210000-00019

3. Ward EM, Raimondo M, Rosser BG, Wallace MB, Dickson RD (2004) Prevalence and natural history of gastric antral vascular ectasia in patients undergoing orthotopic liver transplantation. J Clin Gastroenterol 38(10):898-900. https://doi.org/10.1097/00004836-200411000-00013

4. Dulai GS, Jensen DM, Kovacs TO, Gralnek IM, Jutabha R (2004) Endoscopic treatment outcomes in watermelon stomach patients with and without portal hypertension. Endoscopy. 36(1):68-72. https://doi.org/10. 1055/s-2004-814112

5. Suit PF, Petras RE, Bauer TW, Petrini JL Jr (1987) Gastric antral vascular ectasia. A histologic and morphometric study of "the watermelon stomach". Am J Surg Pathol 11(10):750-757

6. Ito M, Uchida Y, Kamano S, Kawabata H, Nishioka M (2001) Clinical comparisons between two subsets of gastric antral vascular ectasia. Gastrointest Endosc 53(7):764-770. https://doi.org/10.1067/mge.2001. 113922

7. Probst A, Scheubel R, Wienbeck M (2001) Treatment of watermelon stomach (GAVE syndrome) by means of endoscopic argon plasma coagulation (APC): long-term outcome. Z Gastroenterol 39(6):447-452. https://doi. org/10.1055/s-2001-15722

8. Wells CD, Harrison ME, Gurudu SR, Crowell MD, Byrne TJ, Depetris G, Sharma VK (2008) Treatment of gastric antral vascular ectasia (watermelon stomach) with endoscopic band ligation. Gastrointest Endosc 68(2):231-236. https://doi.org/10.1016/j.gie.2008.02.021

9. Abdelhalim H, Mostafa I, Abdelbary MS, Elansary M, Abdo M, Abdel Rahim A (2014) Endoscopic band ligation versus argon plasma coagulation for the treatment of gastric antral vascular ectasia in Egyptian patients with liver cirrhosis. World J Med Sci 10(3):357-361

10. Bull-Henry K, Al-Kawas FH (2013) Evaluation of occult gastrointestinal bleeding. Am Fam Physician 87(6):430-436

11. Sato T, Yamazaki K, Akaike J (2012) Endoscopic band ligation versus argon plasma coagulation for gastric antral vascular ectasia associated with liver diseases. Dig Endosc 24(4):237-242. https://doi.org/10.1111/j.1443-1661. 2011.01221.x

12. Lecleire S, Ben-Soussan E, Antonietti M, Goria O, Riachi G, Lerebours E, Ducrotté $P$ (2008) Bleeding gastric vascular ectasia treated by argon plasma coagulation: a comparison between patients with and without cirrhosis. Gastrointest Endosc 67(2):219-225. https://doi.org/10.1016/j.gie. 2007.10.016

13. Naga M, Esmat S, Naguib M, Sedrak H (2011) Long-term effect of argon plasma coagulation (APC) in the treatment of gastric antral vascular ectasia (GAVE). Arab J Gastroenterol 12(1):40-43. https://doi.org/10.1016/j.ajg. 2011.01.012

14. Selinger CP, Ang YS (2008) Gastric antral vascular ectasia (GAVE): an update on clinical presentation, pathophysiology and treatment. Digestion. 77(2):131-137. https://doi.org/10.1159/000124339

15. Zulli C, Del Prete A, Romano M, Esposito F, Amato MR, Esposito P (2015) Refractory gastric antral vascular ectasia: a new endoscopic approach. Eur Rev Med Pharmacol Sci 19(21):4119-4122

16. Chalhoub JM, Umar J, Groudan K, Hamadeh N, Desilets DJ, GreeffY (2020) Endoscopic band ligation compared to thermal therapy for gastric antral vascular ectasia: a systematic review and meta-analysis. United European. Gastroenterol J 2050640620975243. https://doi.org/10.1177/2050640620 975243

17. Conio M, Gostout CJ (1998) Argon plasma coagulation (APC) in gastroenterology experimental and clinical experiences. Gastrointest Endosc 48(1):109-110

18. Ghobrial C, Rabea M, Mohsen N, Eskander A (2019) Gastric antral vascular ectasia in portal hypertensive children: endoscopic band ligation versus argon plasma coagulation. J Pediatr Surg 54(8):1691-1695. https://doi. org/10.1016/j.jpedsurg.2018.07.015

\section{Publisher's Note}

Springer Nature remains neutral with regard to jurisdictional claims in published maps and institutional affiliations.

\section{Submit your manuscript to a SpringerOpen ${ }^{\circ}$ journal and benefit from:}

- Convenient online submission

Rigorous peer review

- Open access: articles freely available online

- High visibility within the field

Retaining the copyright to your article

Submit your next manuscript at springeropen.com 